\title{
PLASMA SPRAYED HYDROXYAPATITE COATINGS MODIFIED WITH SILVER NANOPARTICLES
}

\author{
Mikhail Ignatev ${ }^{l)^{*}}$, Tomasz Rybak ${ }^{l)}$, Gerard Colonges ${ }^{2)}$, Wolfram Scharff ${ }^{3)}$, Swen Marke ${ }^{3)}$ \\ ${ }^{1)}$ Instytut Obróbki Plastycznej, ul. Jana Pawła II 14, 61-139 Poznań, Poland \\ 2) Projection Plasma Systeme, Z.I. du Colombier, 12220 Montbazens, France \\ 3) IfU Diagnostic systems GmbH, Gottfried-Schenker Str. 18, 09244 Lichtenau, Germany
}

Received: 13.06 .2012

Accepted: 19.11.2012

*Corresponding author: e-mail: ignatiev@inop.poznan.pl, Tel.: +48 6165705 55, Zaktad

Zaawansowanych Technologii Kształtowania, Instytut Obróbki Plastycznej, ul. Jana Pawła II 14, 61-139 Poznań, Poland

\begin{abstract}
Metallic silver, silver nanoparticles (AgNp) and nanocomposites based on silver are widely used in medicine, due to their antibacterial and antiseptic properties. The main goals of the present work were: (1) research of various types of liquids containing AgNp (including AgNp produced by biosynthesis technology using dessert plants (nopal, agave) extracts to reduce the silver); (2) research of sedimentation from liquids of $\mathrm{AgNp}$ on the surface of Hydroxyapatite (HA) implant coatings deposited by plasma spraying; (2) preliminary evaluation of antibacterial properties of HA coating modified with AgNp. The first test shows significant antibacterial activity of HA coatings containing AgNp produced by biosynthesis technology.
\end{abstract}

Key words: coating, plasma spraying, hydroxyapatite, silver nanoparticles

\section{Introduction}

A hydroxyapatite $\left(\mathrm{HA}-\mathrm{Ca}_{10}(\mathrm{PO} 4)_{6}(\mathrm{OH})_{2}\right)$ is one of frequently used bioactive materials, because it forms about $80 \%$ of the inorganic part of bone, tooth enamel and dentine. Applications of HA include the coating of implants, periodontal treatment, alveolar ridge augmentation, maxillofacial surgery and otolaryngology [1].

It is known that silver ions exhibit strong antibacterial effects towards a broad spectrum of bacterial strains. Due to the excellent antibacterial activities, silver nanoparticles (AgNp) and AgNp-containing composites are widely used in many bactericidal applications [2-3]. Various types of HA-based composites containing $\mathrm{AgNp}$ were synthesized and their antibacterial properties were studied: Ag-doped hydroxyapatite layers prepared by PLD method [4], $\mathrm{HA}+$ polyvinylpyrrolidone+AgNp (HA/PVP) [5], bovine femur bone HA+AgNp [6].

HA coatings have good potential as they can exploit the biocompatible and bone bonding properties of the ceramic, while utilising the mechanical properties of substrates such as Ti6Al4V and other biocompatible alloys [7].

Recently, only plasma spraying is the only commercially accepted method for producing hydroxyapatite coatings [8]. Nevertheless, infection on and around HA coated implants still remains a problem, which is usually difficult to treat, and may lead to eventual implant removal [9]. Infection of orthopedic implants often leads to inflammation immediately after surgery and increases patient morbidity due to repetitive operations. Additional methods are necessary to prevent infection. One of the ways is to make the implant surface antibacterial by impeding 
biofilm formation. The continuous presence at bone-implant area of $\mathrm{Ag}$ with superior antimicrobial properties is the most promising way to solve existing infection problems. Due to the excellent antibacterial activities, silver nanoparticles are widely used in biomedical fields to control infections [10]. Nevertheless, methods for modification of HA coatings with AgNp are not well developed. The main goal of the present research is the development of a method for modification of HA plasma sprayed coatings with AgNp. The following method was applied to reach this goal: sedimentation of $\mathrm{AgNp}$ on HA coating surface from liquids containing AgNp.

\section{Experimental materials and methods}

\subsection{Deposition of Hydroxyapatite coating by plasma spraying}

Plasma Spraying is the most widely applied method to deposit HA coating onto titanium alloy prostheses (90\% of implant manufacturers use this type of coating deposition [8]). The method consists of injection of HA particles into a high temperature (>10000 K) plasma jet [11]. Intensive HA particles heating leads to dehydration and decomposition of HA and fast cooling of crystal phases in the solid core at impact results in conservation of high temperature phases [12]. The fraction of phases in sprayed coatings is the most important factor that determines their biological behaviour, such as dissolution of the coating in vivo [13]. That is why optimisation of coating process is very important factor to reach the desired coating quality.

The company Projection Plasma System (2PS, France) has 23 years of experience in plasma spraying of hydroxyapatite on surgical implants. 2PS developed original own spraying equipment and related technology for HA coating deposition. HA coating were deposited on the flat surface of Ti-alloy disk samples by 2PS under conditions that are typical for production of HA coatings on real implants. These samples were used in further research of $\mathrm{AgNp}$ sedimentation on the HA coating surface. Typical image of HA spraying process and Ti-alloy disk samples with HA coatings are presented in Fig. $1(\mathbf{a}, \mathbf{b})$.
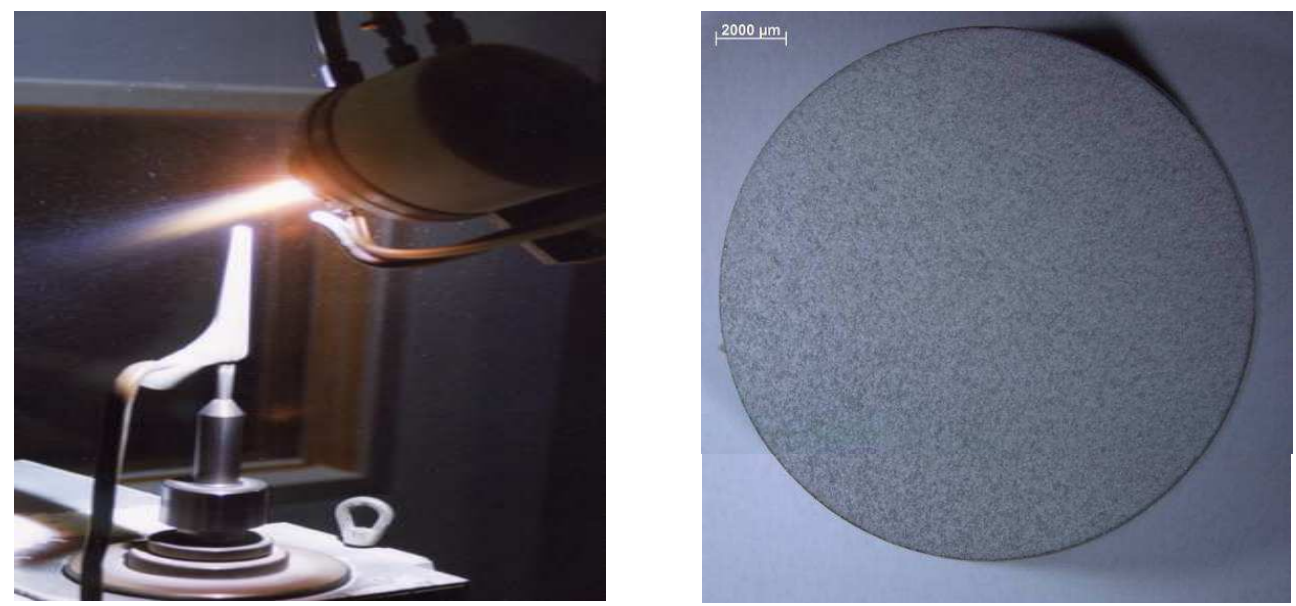

Fig. 1 a-Plasma Spraying of HA at 2PS; b -Ti Disk coated with HA.

\subsection{Characterisation of liquids containing AgNp}

One of the main research axis of NANOMINING Project is the development of novel AgNp biosynthesis technology using dessert plants extracts (nopal, agave) to reduce the silver. This technology is developing by the Mexican research group at the Centro de Investigacion en 
Quimica Aplicada (CIQA) [14]. Final product is supplied in the form of liquid containing AgNp. Similar liquids obtained by other methods (that are usually more expensive) are available on the market. That is why it was decided to use for the present research various types of commercial liquids to speed up the development of method of AgNp sedimentation on HA surface. Parameters of various liquids applied in experiments are presented in Table 1 (technical data are provided by manufacturers).

Table 1 Parameters of liquids containing AgNp

\begin{tabular}{|lcc|}
\hline Manufacturer & $\begin{array}{c}\text { AgNp mean size } \\
{[\mathbf{n m}]}\end{array}$ & $\begin{array}{c}\text { AgNp concentration } \\
{[\mathbf{m g} / \mathbf{l}]}\end{array}$ \\
\hline \hline Sigma Aldrich & 10 & 108 \\
Particular GmbH & 66 & 106 \\
Particular GmbH & 15 & 100 \\
CIQA & 8 & 185 \\
\hline
\end{tabular}

The Surface Plasmon Resonance Spectroscopy (SPR) was applied for characterization of initial liquids and liquids after various stages of sedimentation experiments. When metal nanoparticles are excited by electromagnetic radiation, they exhibit collective oscillations of their conduction electrons known as localized surface plasmons. The wavelength corresponding to the extinction maximum, $\lambda_{\max }$, of the SPR is highly dependent on the size, shape, and dielectric properties of the metal nanoparticles [15]. This technique uses ultraviolet-visible (UV) spectrometer with high sensitivity. A strong broad SPR absorption band is observed in the absorption spectra of silver nanoparticles. The position of the surface plasmon resonance peak was used to calculate the particle size. The relation between the surface plasmon resonance wavelength and the particle size was determined by theoretical experiment. The transmittance and the reflectance of a thin composite layer (liquid with $\mathrm{AgNp}$ ) were calculated. The peak position is shifted depending on nanoparticle size. The measurements were performed to study the stability of liquids in time (tendency of $\mathrm{AgNp}$ to agglomeration: during 10 weeks SPR measurements were performed for the same liquids) and to control changes in liquids after experiments (agglomeration).

\subsection{Sedimentation of AgNp on HA coating surface}

For modification with AgNp of medical materials relatively simple methods should be applied to ensure high productivity and cost efficiency. For example, the impregnation of silver nanoparticles in cotton fabrics was carried out by Duran's method [16]. Cotton fabrics were washed, sterilized, and dried before use. The fabrics were submersed in a filtrate of AgNp, shaken at $600 \mathrm{rpm}$ for $24 \mathrm{~h}-60 \mathrm{~h}$, and dried at $70^{\circ} \mathrm{C}$. The $\mathrm{AgNps}$ absorption in fabrics was $2 \%$ of the initial concentration [17]. Other researchers for improvement of antibacterial properties of various materials also apply liquids containing $\mathrm{AgNp}$ and similar sedimentation methods [18]. The adsorption is the main physical phenomenon responsible for AgNp sedimentation on the material surface [18]. It depends strongly on the type of material to be modified with AgNp.

In our experiments relatively simple installation was used for $\mathrm{AgNp}$ sedimentation on HA surface. It consists of chemical flask that is placed on rotation unit providing maximum rotation speed $600 \mathrm{rpm}$. The disk samples were suspended with the help of stand-alone holder inside of the flask. The time of samples treatment was varied from 24 to 60 hours. The sedimentation is registered on variation of $\mathrm{AgNp}$ concentration in a solution that is reflected in a spectrum as falling of intensity of an appropriating absorption peak. After the first experiments, it was 
decided to apply Hielscher Ultrasonic Homogenizers (HUH) with $400 \mathrm{~W}$ power to avoid AgNp agglomeration and to reach more uniform distribution of $\mathrm{AgNp}$ on $\mathrm{HA}$ surface. The general view of the installation with HUH is presented in Fig. 2.

The evaluation of antibacterial properties of HA coatings was performed both for initial HA coatings and HA coatings modified with AgNp.
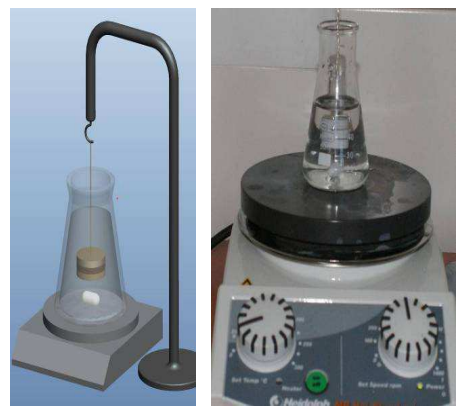

Fig. 2 Installation for sedimentation of $\mathrm{AgNp}$ on HA surface: general view.

\section{Results and Discussion}

Fig. 3 shows the free surface of HA coating deposited on Ti-alloy disk at conditions typical for industrial process (similar to coating deposition on real Ti-alloy implants by 2PS). The HA surface is characterized by low porosity and presence of micro-cracks. Micro-cracking arises from shrinkage of the splat during quenching and subsequent differential thermal expansion coefficient between substrate and coating. Certain amount of micro-cracks is acceptable for practical applications according to industrial standard. The SEM image of the surface of coated sample shows presence of small spherical HA particles. They are less in size than initial HA particles that is in the range from $65-150 \mu \mathrm{m}$ with median diameter $95 \mu \mathrm{m}$. This is a result of particle partial melting and evaporation in plasma jet.
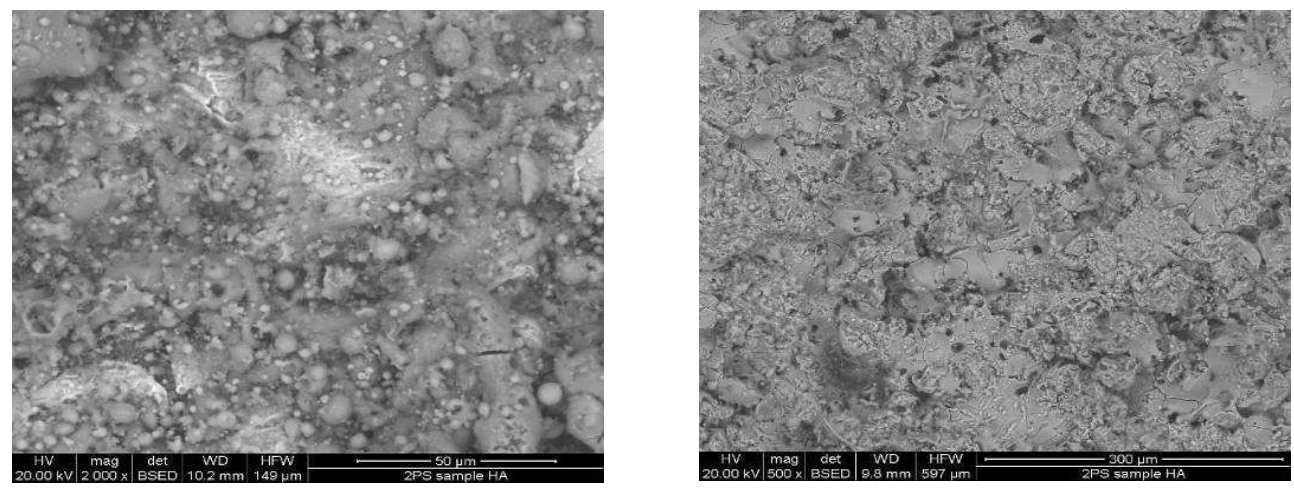

Fig. 3 SEM image (different magnifications) of free surface of HA coating deposited on Tialloy disk at conditions typical for industrial process. 
The EDAX analysis of as coated HA coating (Fig. 4) shows the presence of Ca (46-48 wt\%), $\mathrm{P}(18-21 \mathrm{wt} \%)$ and $\mathrm{O}(27-33 \mathrm{wt} \%)$ that is in a good accordance with optimum HA coating composition [19].

The parameters of spaying process should be adjusted in order to provide mainly partial particle melting keeping solid state of the particle core. Particle-in-flight parameters (velocity and temperature) were measured by diagnostic system developed by the Project partner IfU Diagnostic Systems GmbH to optimize spraying process parameters [20].
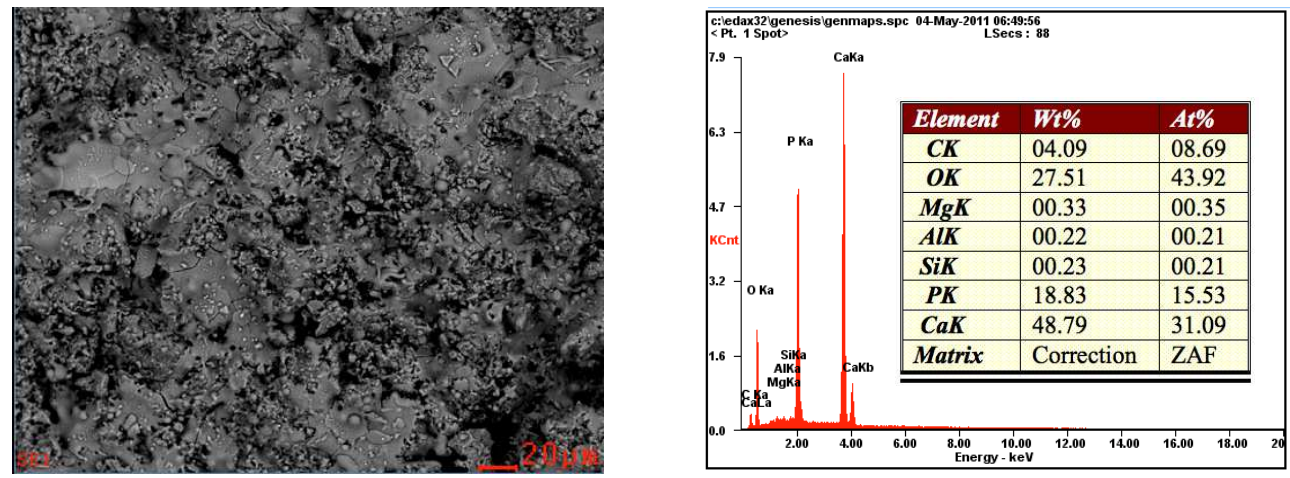

Fig. 4 EDAX analysis of HA coating.

Results of statistical analysis of particle surface temperature and particle velocity of HAspraying process at standard conditions (measure time 1,6 ms) are presented in Fig. 5 in the form of histogram. HA particles have velocity in wide range from 150 to $500 \mathrm{~m} / \mathrm{s}$. Such velocities provide required deformation of particles for formation of a dense HA coating with good adhesion to substrate. Particle temperature histogram shows narrow spread in values with relatively sharp maximum near $1800^{\circ} \mathrm{C}$ that is higher than $\mathrm{HA}$ melting point $\left(1100^{\circ} \mathrm{C}\right)$. According to simulation of particle heating in plasma jet the average particle volume temperature is less than surface temperature by $800^{\circ} \mathrm{C}-1500^{\circ} \mathrm{C}$ for particles in the range $50-150$ $\mu \mathrm{m}$ [21]. As a result, nominal spraying parameters ensure melting only surface layers of individual particle that is a necessary condition for formation of high quality coating.
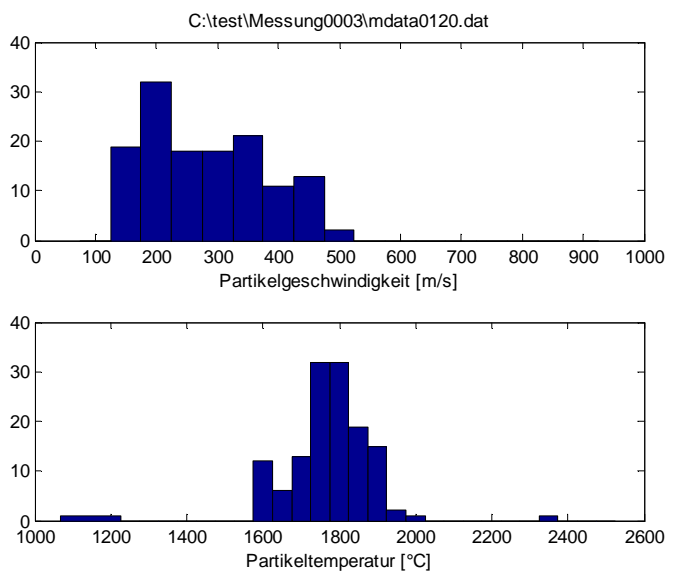

Fig. 5 Surface temperature and particle velocity of HA-spraying process at nominal conditions. 
The coating thickness was characterized using cross section that is shown in Fig. 6. The thickness of HA coating is in the range $80-120 \mu \mathrm{m}$ that corresponds to the thickness of coating usually applied for real orthopedic implants.

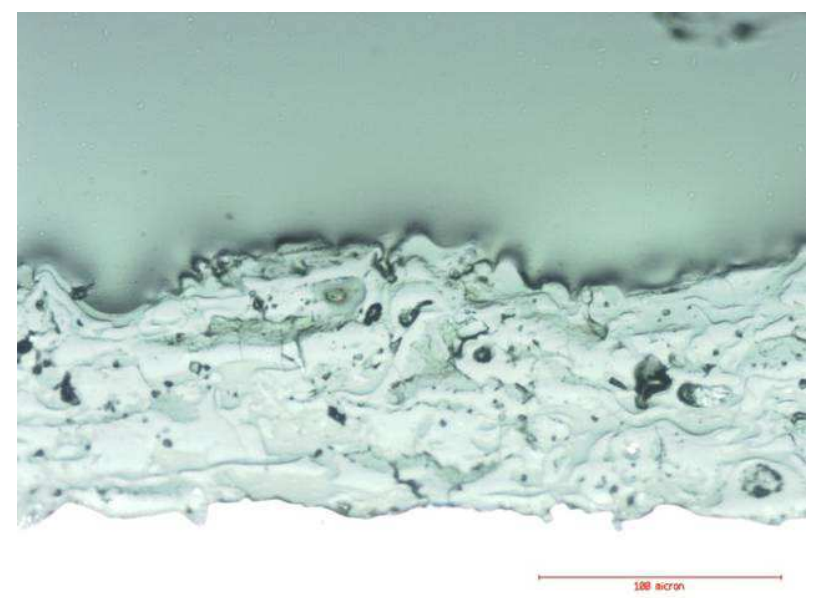

Fig. 6 Image of cross section of typical HA coating using for orthopedic implants.

The optimization of AgNp sedimentation process was done with the help of variation of the following parameters: AgNp size, time of treatment, Ultrasonic homogenization power. Results of experiments with various liquids containing AgNp show that the most suitable for uniform sedimentation of AgNp on HA surface is the liquid produced by Particular $\mathrm{GmbH}$ with average particles size $15 \mathrm{~nm}$ and concentration 100mg/l. $125 \mathrm{ml}$ of Particular and CIQA liquid were used in the experiment on preparation of disk samples for in vitro tests of antibacterial activity. It was found that to get desired results time of sedimentation should be increased to $60 \mathrm{~h}$. There were 8 disk samples processed for in-vitro tests. Samples were placed at 2 levels, 4 samples on each level over the magnetic dipole. 1 sample of 4 from each level was observed using HR-SEM. SEM image of the sample surface after sedimentation and results of EDAX analysis of average silver concentration is shown in Fig. 7. The distribution of Ag in different areas of the sample is practically uniform and average $\mathrm{Ag}$ concentration varies from 13 to $18 \%$ wt..

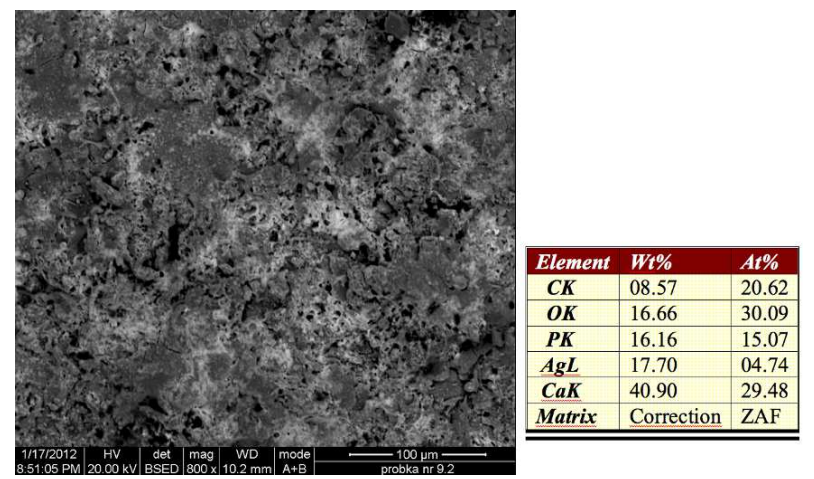

Fig. 7 SEM image and result of EDAX analysis of average Ag concentration on the surface of Ti-alloy disk surface. 
HR-SEM images of HA surface containing AgNp are presented in Fig. 8. The most important feature is the absence of essential agglomeration on the HA coating surface. Only accidental AgNp agglomerates with typical size 100-150 nm are observed. Obtained results are suitable for further in vitro tests of $\mathrm{HA}+\mathrm{AgNp}$ coatings.
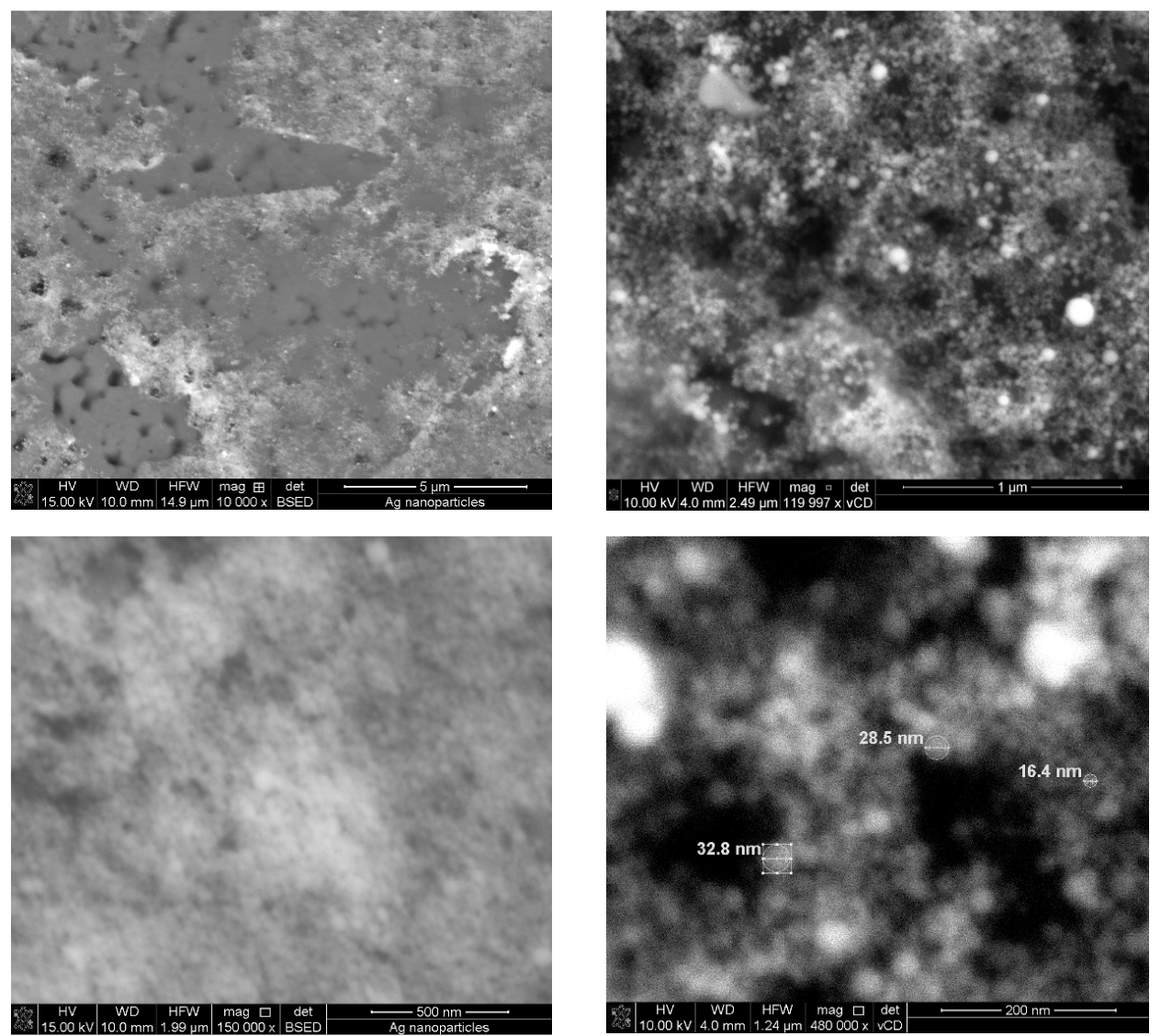

Fig. 8 HR-SEM images of AgNp on HA coating surface at various magnifications.

Changes in the liquids containing AgNp both in time (stability and tendency to agglomeration) and after experiments (variation of concentration as a result of sedimentation) can be registered on variation of their absorption spectra. The absorption peak of surface plasmon resonance (SPR) is very well to be seen in liquids with $\mathrm{AgNp}$ at $421-424 \mathrm{~nm}$. During 63 days 5 measurements were performed at different days to test in time stability of the liquid. Agglomeration process in the liquid shifted the peak position. Strong in time reduction of absorption efficiency of SPR was observed in experiments (Fig. 9). The analysis gives a growing (near 2.5 times) of the calculated mean $\mathrm{AgNp}$ size during the observation period (Fig. 9). A calculation of the concentration using surface plasmon peak was not possible, because the measured (and calculated) values were not stable. Here the problem of unknown scattered light is disturbing. Also the second unknown peak gives a big problem for the scattered light estimation. Note, that inside the samples there are a lot of bigger sized particles (several $\mu \mathrm{m}$ in diameter, because they are visible) it could be caused, probably, by formation of large- 
scale clusters during sedimentation process. Further adjustment of methodology to control spectrum of $\mathrm{AgNp}$ containing liquids will be realized in the frame Project to control sedimentation process and agglomeration.

The set of Ti-alloy disk samples were treated with AgNp liquids under nominal conditions for further cytotoxicity and antibacterial tests.

Preliminary evaluation of cytotoxicity properties of HA coatings was performed by BioCentrum (Kracow, Poland) both for samples with initial HA coating and for samples with HA coating modified with AgNp. All samples with HA coating containing AgNp have shown cytotoxic effect against bone cancer SaOS-2 cells.

Wide range of antibacterial and cytotoxicity tests was performed by Project partner Poznan University of Medical Sciences-Department of General Orthopedics, Musculoskeletal Oncology and Trauma Surgery. Strong cytotoxic effect of HA coatings containing AgNp was also confirmed by this research. Significant antibacterial activity has been noted in the case of the samples with HA coating containing AgNp produced by Project partner CIQA (Mexico) by biosynthesis technology.

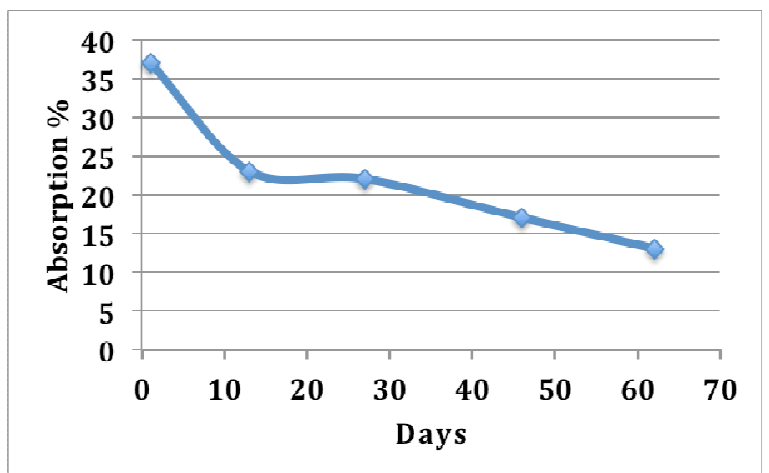

Fig. 9 Monitoring during 63 days the position of absorption peak of visible-near IR spectrum of Particular liquid (initial characteristics: AgNp mean size - $66 \mathrm{~nm}$, concentration $106 \mathrm{mg} / \mathrm{l})$ after experiments on $\mathrm{AgNp}$ sedimentation.

The further research on optimisation of AgNp concentration on the surface of HA coating should be performed to reach desired antibacterial properties and to decrease cytotoxic effect.

\section{Conclusion}

The most suitable liquids containing AgNp for treatment of HA coatings are liquids from CIQA (mean particle size $8 \mathrm{~nm}$ ). The nominal (for deposition of HA coatings to be modified with $\mathrm{AgNp}$ ) particle-in-flight parameters (measured by diagnostic system) are: particle velocity in the range $150-500 \mathrm{~m} / \mathrm{s}$; maximum temperature $1800^{\circ} \mathrm{C}$; coating thickness $80-120 \mu \mathrm{m}$. The optimum parameters of sedimentation process are: rotation speed $600 \mathrm{rpm}$, time of treatment 60 hours, power of UV homogeniser 400W. The liquids containing AgNp has a tendency for nanoparticle agglomeration after an experiment that is why it can be used only one time. The first test results show strong cytotoxic effect of all HA coatings containing AgNp. Significant antibacterial activity has been noted in the case of the samples with HA coating containing AgNp produced by Project partner CIQA (Mexico) by biosynthesis technology. The further research on optimisation of $\mathrm{AgNp}$ concentration on the surface of HA coating should be performed to reach desired antibacterial properties and to decrease the cytotoxic effect. 


\section{References}

[1] B.D. Ratner: Biomaterials Science: An Introduction to Materials in Medicine, edition 1.1, Academic Press, San Diego, 2004

[2] M. Singh, S. Singh, S. Prasad, I.S. Gambhir: Digest Journal of Nanomaterials and Biostructures, Vol. 3, 2008, No. 3, p. 115-121

[3] J.P. Ruparelia, A.K.Chatterjee, S.P. Duttagupta, S. Mukherji: Acta Biomaterialia, Vol. 4, 2008, No. 3, p. 707-716

[4] M. Jelínek, et al.: Applied Physics A, Vol. 101, 2010, No. 4, p. 615-620

[5] H. Oudadesse, A. Mostafa, Y. Legal, G. Cathelineau: Elaboration and Physicochemical Behaviour of Nano Hydroxyapatite / Silver Nanoparticles Biocompsite after "In Vitro" Assays, In: Recent Advances in Applied \& Biomedical Informatics and Computational Engineering in Systems Applications Florence, 2011, p. 71-76

[6] R. Nirmala, et al.: Journal of Nanoparticle Research, Vol. 13, 2011, No. 5, p. 1917-1927

[7] W.R. Lacefield: Annals of the New York Academy of Sciences, Vol. 523, 1988, p. 72-80

[8] L. Sun, C. Berndt, K. A. Gross, A. Kucuk: Journal of Biomedical Materials Research, Vol. 58, 2001, No. 5, p. 570-592

[9] L. Zhao, P.K. Chu, Y. Zhang, Z. Wu: Journal of Biomedical Material Research B, Vol. 91, 2009, No. 1, p. 470-480

[10] V. K. Sharma, R. A. Yngard, Y. Lin: Advances in Colloid and Interface Science, Vol. 145, 2009, No. 1-2, p. 83-96

[11]L. Pawlowski: The Science and Engineering of Thermal Spray Coating, $2^{\text {nd }}$ edition, Wiley, Chichester, 2008

[12]R. Jaworski, L. Pawlowski, C. Pierlot: Suspension Plasma Sprayed Titanium Oxide and Hydroxyapatite Coatings, In: International Thermal Spray Conference 2009, Las-Vegas, Nevada, 2009, p. 156-16

[13]R. Tomaszek, L. Pawlowski, L. Gengembre, J. Laureyns, A. Le Maguer: Surface Coating Technologies, Vol. 201, No. 16-17, 2007, p. 7432- 7440

[14] J. González García, A.S. Ledezma J. Romero-García, I. Moggio, E. Arias-Marin, M.E. Ramos Aguińaga: Biosynthesis of Silver Nanoparticle using desert plants, In: International Conference on Polymers and Advanced Materials POLYMAT-2011, Huatulco, Oaxaca, 2011, p. 123-125

[15] J. R. Krenn, et al.: Applied Physics Letters, Vol. 77, 2000, No. 21, p. 3379-3382

[16] N. Duran, et al.: Journal of Nanoparticles Research, Vol. 12, 2010, No. 1, p. 285-292

[17] N. Durán, P. D. Marcato, G. I. H. De Souza, O. L. Alves, E. Esposito: Journal of Biomedical Nanotechnology, Vol. 3, 2007, No. 2, p. 203-208

[18]E. Egorova: Biological effects of silver nanoparticles, In: Silver nanoparticles: properties, characterization and applications, Ed. A. E. Welles, Nova Science Publishers, New York, 2010

[19] M. Mittala, S. K. Natha, S. Prakash: Journal of Minerals \& Materials Characterization \& Engineering, Vol. 10, 2011, No.11, p.1041-1049

[20]W. Scharff: Modern diagnostics in coating technologies, In: Conference Advanced technologies for forging tool life improvement, Opelenica, Poland, 2012, p. 15-18

[21]L. A. Dombrovsky, M. B. Ignatiev: High Temperature, Vol. 39, 2001, No.1, p. 134-141 


\section{Acknowledgements}

The research leading to these results has received funding from the European Union Seventh Framework Programme FP7/2007-2013 under grant agreement No. NMP4-CP-2011-263942 (NANOMINING Project "Development of New Nanocomposites Using Materials from Mining Industry"). Research work financed from public funds for science in period 2011- 2013, granted for realization of international co-financed project.

Authors are grateful to research team of Metal Forming Institute for samples preparation and study, BioCentrum for antibacterial evaluation of HA coatings, Poznan University of Medical Sciences-Department of General Orthopedics, Musculoskeletal Oncology and Trauma Surgery for wide range of antibacterial and cytotoxicity tests and CIQA for preparation of AgNp liquids by biosynthesis. 